\title{
ADAPTIVE E-LEARNING AND ITS EVALUATION
}

\author{
Kateřina Kostolányová, Jana Šarmanová, \\ Ondřej Takács \\ University of Ostrava \\ katerina.kostolanyova@osu.cz
}

\section{Abstract}

This paper introduces a complex plan for a complete system of individualized electronic instruction. The core of the system is a computer program to control teaching, the so called "virtual teacher". The virtual teacher automatically adapts to individual student's characteristics and their learning style. It adapts to static as well as to dynamic characteristics of the student. To manage all this it needs a database of various styles and forms of teaching as well as a sufficient amount of information about the learning style, type of memory and other characteristics of the student. The information about these characteristics, the structure of data storage and its use by the virtual teacher are also part of this paper.

We also outline a methodology of adaptive study materials. We define basic rules and forms to create adaptive study materials. This adaptive e-learning system was pilot tested in learning of more than 50 students. These students filled in a learning style questionnaire at the beginning of the study and they had the option to fill in an adaptive evaluation questionnaire at the end of the study. Results of these questionnaires were analyzed. Several conclusions were concluded from this analysis to alter the methodology of adaptive study materials.

\section{Key Words}

e-learning, adaptability, adaptive learning environment, individualized instruction, learning style, evaluation, analysis
ARTICLE INFO

Article type

Full research paper

doi: 10.7160/eriesj.2012.050404

Article history

Received: September 26, 2012

Received in revised form: November 23, 2012

Accepted: December 5, 2012

Available on-line: December 30, 2012

Kostolányová, K., Šarmanová, J., Takács, O. (2012) “Adaptive e-learning and Its Evaluation", Journal on Efficiency and Responsibility in Education and Science, Vol. 5, No. 4, pp. 212-225, ISSN 1803-1617, [on-line] www.eriesjournal.com/_papers/article_190.pdf [2012-12-30]. doi: 10.7160/eriesj.2012.050404 


\section{Introduction}

Individualized instruction is nothing new in the field of education. This approach has been recommended in the form of a principle since the age of J. A. Komenský. The key point of individualized approach is the students themselves, studying. Each is an individual from many points of view:

- their talent differs in different fields of study,

- their entry knowledge of the subject they currently study can differ,

- they prefer different learning style than others,

- they can have different type of memory,

- their memory is better trained than the memory of others,

- they can have different motivation to learn, different family background, different study habits.

The ideal teacher is able to adapt to the needs of the student. They know the preferences of the student and their permanent characteristics. They are also able to recognize student's current shortage of knowledge and adapt the speed and style of teaching appropriately. Taking all this into consideration can produce an optimal teaching instruction.

During self-study, students usually use textbooks. A good textbook can be understood as a different form of teacher. The author puts in their optimal teaching instruction, their scope and detail of presented information.

It is necessary to create a teaching system that will take student's preferences and the absence of "live" teacher into account when presenting new information. To choose a suitable learning style for a student you need to know their characteristics.

\section{Principle of Making Adaptive Environment}

Nowadays, LMS systems are used to store study materials, control instruction, register students, record students' activities and their results. However, LMS systems do not take learning styles into consideration.

A global approach to deliver schoolwork to students is provided regardless of their learning styles and levels of knowledge [Brusilovsky, 1998; Brusilovsky, 2001]. If the student is not participating in face to face communication with the teacher, they use textbooks to study. Authors usually use global approach to structure topics in the textbooks, not taking learning styles into consideration [Kulič, 1980].

The electronic adaptive environment, however, follows the behavior and characteristics of a particular student. Before the student starts their study of a particular subject, they fill in a questionnaire to find out their preferences in various areas of study:

- sensory perception,

- social aspects,

- emotional aspects,

- learning tactics: ability to be systematic, study approach, study methods and self-regulation.

Study material is prepared for particular users in relation to their abilities, preferences and needs, taking learning styles into consideration. To respect differences among its users, the system cannot be anonymous. Data collection of student's information is done in several steps.

The most important step is the evaluation of the student. It means that the student will be tested before entering the course (test results will be classified as "constant parameters") and 
during the course (test results will be classified as "dynamic parameters"). These dynamic parameters are used to modify the course path.

The objective of adaptive instruction is not only to adapt the instruction to student's needs. In case the student has satisfying study habits, there is no need to direct their effort. It would be more effective to offer different methods and learning styles to them that they might find interesting and that would be more effective for their study than those they have used so far. On the contrary, there are students who do not have satisfactory study habits. Their study is superficial without understanding the essence of the lesson and they do not have the ability to put what they have learnt into practice. In this case, the task of adaptive algorithms is to teach these students a better learning style.

\section{Adaptive Systems}

"A learning environment is considered adaptive if it is capable of: monitoring the activities of its users; interpreting these on the basis of domain-specific models; inferring user requirements and preferences out of the interpreted activities, appropriately representing these in associated models; and, finally, acting upon the available knowledge on its users and the subject matter at hand, to dynamically facilitate the learning process" [Paramythis, 2003].

Adaptive learning can have many forms that can be divided to following categories (Paramythis, 2003): adaptive interaction, adaptation of content, content discovery and assembly, and adaptive collaboration support.

The first category, Adaptive Interaction, adapts the user interface of the learning environment, such as colour schemes, fonts, etc. together with the structure of the user interface and the order of system's actions.

The second category, Adaptive of Content, changes the structure and presentation of the course in a way, that suites user's characteristics and optimizes quality and time of learning. This way of adaptation involves dynamical changes in the navigation elements of the course and its structure and dynamical selection of its suitable parts.

The third category, Content Discovery and Assembly, selects the most beneficial learning material from potentially distributed sources on the basis of users known characteristic and goals.

The fourth and final category, Adaptive Collaboration Support, is focused on the communication between multiple persons and on different kinds of user collaboration. Adaptive techniques can be used to facilitate the communication and collaboration, ensure a good match between users, etc.

This paper is focused on the Adaptive of Content.

\section{Systems that Adapts the Content}

There already exists some systems that adapts the content to each individual student. But they are too limited.

System AHA! (Adaptive Hypermedia for All) [De Bra, 2003] can adapt the contentent, but it is very hard to do, because each author has to design everything: what properties he will measure, how he will measure it, what changes in the content he will do to each set of properties.

System PEL-IRT (Personalized E-Learning system based on Item Response Theory) [Chih-Ming 2005] and Feijoo.net [Kalyuga, 2005] adapts content in too big parts and is limited to only two properties of students. 


\section{Research of Adaptation of Content}

This paper is focused on the adaptation of learning content and describes how exactly it is done. Research in this area is a long term process, because there are many stages that must be finished before the research can start. The adaptive learning system must be designed and implemented first, so there is some environment to do research in. After this, group of authors must design and create the content of the system: adaptive teaching support. When these tasks are finished, students can begin the studying in this adaptive system, we can measure their progress and make some conclusions.

Objective of this paper is to describe the prototype of adaptive system, adaptive teaching system and the results of preliminary research. The hypotheses of our research are:

1. Students gain more knowledge and skills when they learn from adaptive teaching supports than if they learn from common textbooks.

2. Students are more motivated to learn from adaptive teaching supports than from common textbooks.

3. Students are learning more quickly from adaptive teaching supports than from common textbooks.

4. Students can learn to learn more from adaptive teaching supports than from common textbooks.

In this early stage we use only simple questionnaire survey as research method to get some early feedback, so only first two hypotheses were considered.

\section{Materials and Methods}

\section{Design of Adaptive LMS Structure}

Electronic adaptive environment consists of three modules - student's module, author's module and adaptive module (figure 1).

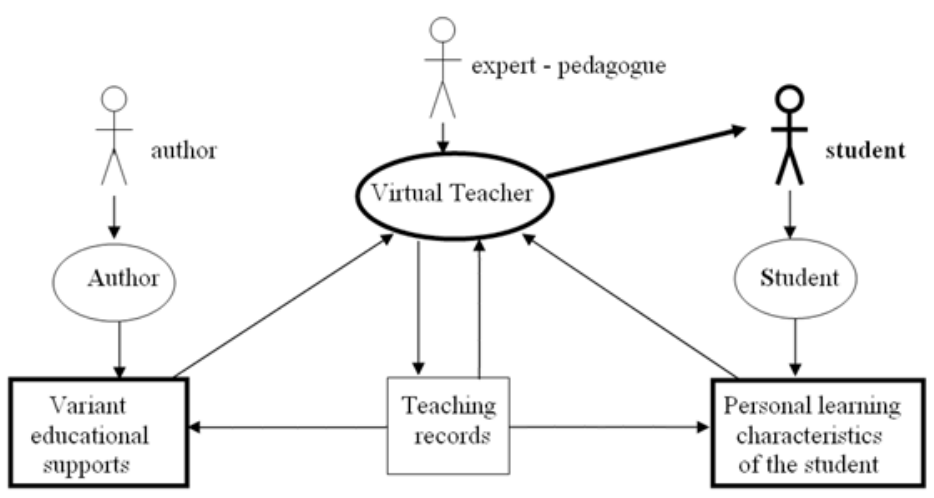

Figure 1: Model of adaptive learning environment

\section{Student's module}

In this module, student plays the key role. From all the characteristics of the student we should pay the most attention to their learning style. Nowadays, many classifications of learning styles exist. For this reason, the following characteristics to be used in e-learning has been chosen [Kostolányová, 2010; Kostolányová, 2011b].

The chosen characteristics were classified into these categories: 
1) sensory perception describes the preferred form of information delivery to the student. Visual type of student prefers schemes, pictures, tables and graphs. Auditory type of student prefers spoken language and contact with other people. Kinesthetic type of a student prefers demonstration, models and practical information. Verbal type of student prefers information in a text form.

2) social aspects deal with the most convenient study environment for the student. Do they like to study with other schoolmates? Do they like to study with the help of the teacher? Do they prefer to study individually?

3) emotional aspects deal with feelings and attitudes of student that influence the process of learning. The most important characteristic from this category is motivation of which two parts can be observed - external and internal. While external conditions such as job or family requirements are the source of external motivation, the source of internal motivation is the student her/himself.

4) learning tactics describe the "methods" of how students study. Ability to be systematic describes how the student studies. Do they study step by step according to the instructions (pole: order) or do they study in a random order (pole: free hand)?

5) study approach can be divided into two groups. In the first group there are tactics including theoretical deduction. Students who prefer these tactics like to focus on details. In the second group there are tactics that include experiments. Students who prefer these tactics like to put their acquired knowledge into practice as soon as possible.

6) learning strategy can be divided in detailed tactics with focus on small parts of particular information. From these small parts the "whole picture" is made. The second is the holistic tactics with focus on big parts of abstract information from which the student works their way to details.

7) study conception can be divided in contemplative, strategic and surface learning. In contemplative learning student aims to understand what they learn. In strategic learning student aims to be effective in their learning and wants to achieve the best results. In surface learning student aims to accomplish the minimal requirements only.

8) Self-regulation defines how much the student is able to control their learning process. If they are able to control their learning process successfully, they do not need any external help. If they are not able to control their learning process, they will need precise instruction.

\section{Author's module}

Learning material is important for students to be able to learn independently. The program must have different levels of curriculum conception and various sensory perception forms to correspond with the learning styles of specific students.

Each chapter of each topic delivers well structured instruction to student - chapters are divided into subchapters, paragraphs, etc. We call the smallest coherent part representing a unit of information the "framework". The framework is identical to the lowest level of a numbered text. Each particular framework is divided into an explanatory part, testing part and others (figure 2). The explanatory part is further divided into traditional parts of instruction - theoretical, semantic, consolidating and motivational. By combining the parts mentioned above we obtain different ways of instruction. For the testing part, various categories of questions, exercises and practical tasks have been chosen. The part "others" of a particular framework contains motivational, navigational and accomplishment layers. The 
framework is also divided to variants, where each variant describes the same information in different way. There are four sensory variant that differs in multimedia used and three depth variants that differs in verbosity.

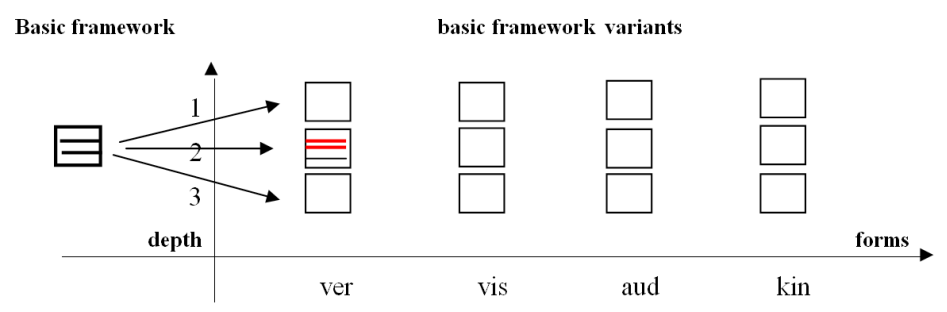

Figure 2: Variations of framework

\section{Adaptive module}

When we prepare adequate study materials (author's module) and include student characteristics (student's module), we lay down the foundations for the adaptive module. Creating the adaptive module was the most demanding. The key aspect was to define the rules that manage the selection of the most suitable parts of frameworks. Afterwards the framework is displayed to the student. Their knowledge is gradually tested in the form of theoretical questions and tasks. If the student finishes the framework successfully, they can continue in their study. Failing that, the student is offered a different approach to learn what they have not understood. There might either be a more detailed explanation or additional examples with further practical use. This should help students finish the framework successfully.
It is necessary to monitor all study activities of the student to know the progress of their study. Dynamic characteristics recorded from their study activities and from self-regulation should be added to the student's static characteristics entered at the beginning of their study. Information about their study activities will be gathered from progress tests.

Frequency of testing can differ - after each chapter, after a particular topic explained, after a study unit. The test results tell us whether the student learnt something new or not, whether they like the suggested strategy for their study or not. Monitoring these dynamic characteristics, a good adaptive algorithm can modify and improve the instruction approach such as changing the way of explanation, varying the way of practice, etc. Above all that, the adaptive algorithm should follow the study objectives and help students achieve these objectives.

\section{Design of Adaptive Textbook}

Methodology for the design of adaptive textbook stems from the general teaching principles of Jan Ámos Komenský, situated learning of Gagné and Bloom's taxonomy of learning objectives. These experts laid down the foundation of learning style strategies. They defined the rules and principles suitable for effective instruction.

When creating the methodology for the design of adaptive instruction materials we took all these teaching principles and the methodology of distance-learning textbook design into consideration.

We used the principle of illustration, self-consciousness, systematic approach, adequacy and permanence of Jan Ámos Komenský. Instruction methods follow the basic steps of study. 
The Gagné's principle of situated learning was used in adaptive instruction as follows: introduction of the lesson, instruction, practice, testing and the end of the lesson. Bloom's theory to define learning objectives in adaptive study materials was used with emphasis on the cognitive area of knowledge. The objectives are defined in relation to the character of study. There are six categories - remember, understand, apply, analyze, evaluate, create [Gagné, 1975; Komenský, 1947 \& 1948].

When considering the possibilities to be used in adaptive instruction we took the design of distance-learning study materials into consideration. One of these ideas is to divide a study material into smaller parts as chapters and subchapters. We call one coherent unit of study a "framework". One such unit includes one main topic. Explanation of a subtopic is in accordance with the theory of Gagné's situated learning. The framework is divided into smaller parts called "layers". The layers will make it possible to adapt the style of instruction to student's needs. What we call the layer of framework is that part of the framework that is homogenous in the steps undertaken during the instruction process (instruction, theory, explanation, practice, testing of knowledge, motivation, control of the lesson) [Kostolányová, 2011a].

Types of layers:

- Explanatory- group of layers containing their own explanation of the material covered. This concerns the following layers:

- $\quad$ T Theoretical - containing theory: definition, terms, rules, algorithms, etc. In terms of education, this is the most important type of layer.
- S Semantic - explaining the introduced terms, formally described theory, containing additional information to the theoretical layer, explaining correlations arising from the theory, etc.

- F Fixation - with the aid of repetition, varied formulations and alternative concepts implemented into the wider context to make it easier to remember the theory.

- R Resolved examples - contains examples of how to apply the theory, resolved "textbook" examples. For students, these are examples of solving given tasks.

- P Practical - contains solving of examples from practice that use the theoretical knowledge.

- Testing - a group of layers for the regular testing of acquired knowledge, and fixation of this theoretical knowledge with the aid of tasks. These layers are:

- Questions - theoretical questions from the material covered. Questions may only serve as control questions for the student, or adaptive algorithms may use them to control the next instruction.

- U Tasks - "textbook" exercises to be resolved.

- X Practical exercises - tasks from practice.

\section{- Other layers}

- M Motivational - motivational information about the subject, lesson or framework, which would justify the benefit of study to the unmotivated student. 
- N Navigational - didactic or organizational information, a certain guide for lessons or the material covered, recommended study methods, etc.

To understand the content of particular layers, we provide examples of some of them below:

Example of a layer focused on the objective of instruction

After finishing the study of this chapter, students will be able:

- to define the basic characteristics of vector and bitmap graphics

- when solving a practical task to define which type of graphics to use (according to advantages and disadvantages of each type)

Example of a motivational layer

Did you know that computers display graphics either in a vector or in a bitmap form? Have you seen any difference between these two forms so far? Don't worry and start our course. When you understand the difference between these two forms, you become more effective while working with graphics.

\section{Example of a theoretical layer}

Bitmap graphics depicts a picture with the help of pixels organized in the form of grid. Each pixel in the grid has a defined place and color so the picture is created as a mosaic.

Example of a semantic layer

When we modify a bitmap picture, we change pixels, not line segments and curves. Bitmap graphics depends on resolution because data describing the picture relate to the grid of a particular size. When we modify a bitmap picture, the quality of the image can change. The changes can be particularly visible when displaying a high resolution picture on a monitor with lower resolution. The image quality is low.
Designing the adaptive textbook is more demanding than designing a regular text or multimedia instruction support. A template was created for the authors who decided to participate in designing the adaptive textbook (Table 1). In this template, authors enter the text of instruction material and the use of multimedia components [Kostolányová, 2011c].

One part requires authors to enter specialized content of instruction (the major part of the template) and to the other, they enter relevant metadata needed to control adaptive instruction (right side of the template).

The authors of instruction materials in adaptive form create textual content, well structured into this template. They also enter the use of multimedia components. Detailed scenarios of how to create adaptive instruction materials are part of the adaptive textbook in the appendix form. 


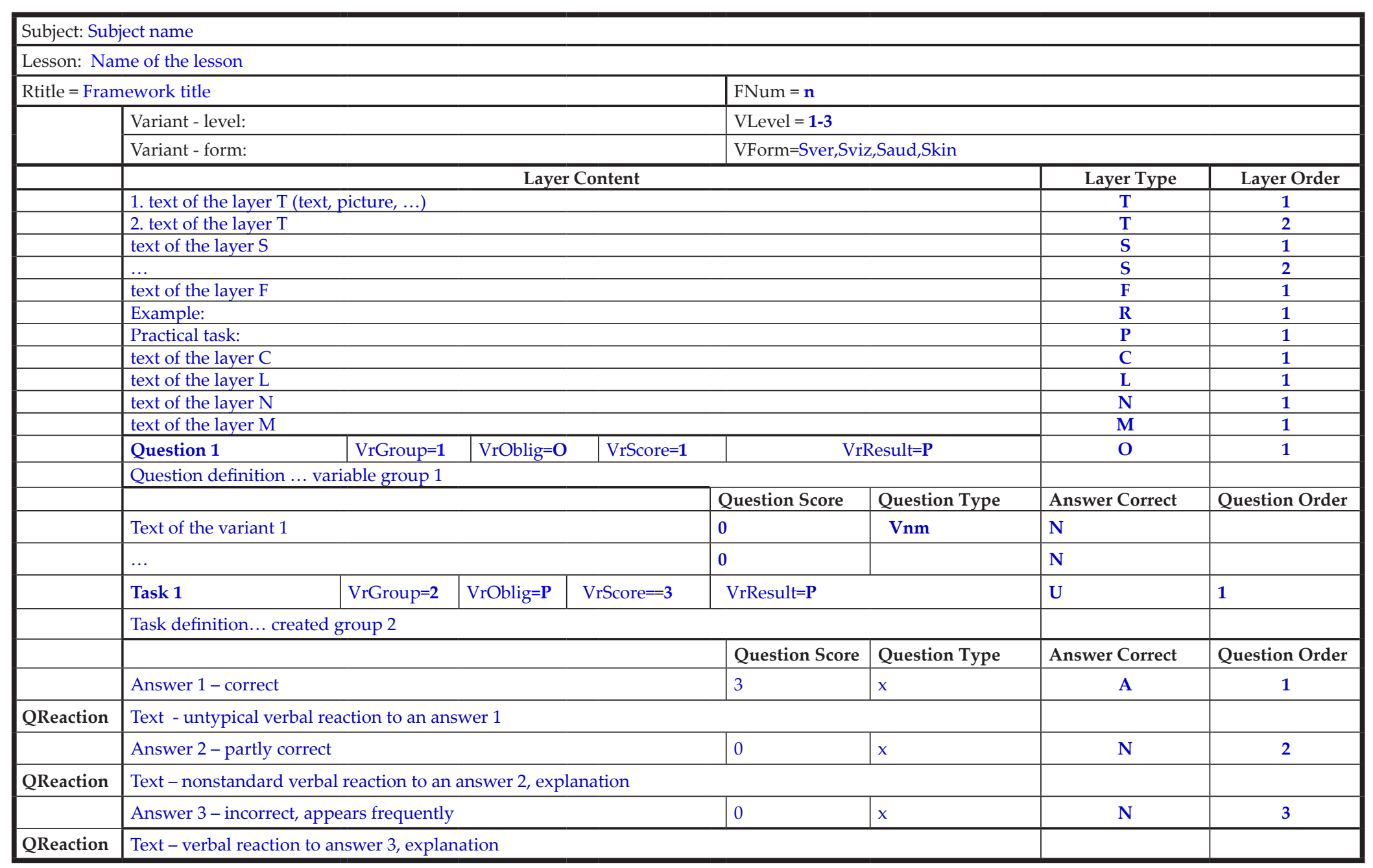

Table 1 - Template to create adaptive study materials 


\section{Control of Instruction by Virtual Teacher}

Each framework, divided into particular layers, will be created in four sensory forms (verbal, auditive, visual, kinesthetic) and in three levels of instruction (standard, with extra support and with extra interesting details for the student). Variants that include a form (sensory forms) and levels of instruction are not able to cover all detected distinctions in style of instruction. The instruction must react to other various characteristics of the student. Analyzing these student's characteristics, we concluded that the instruction can also differ in order of particular parts of instruction and can revise tests and organizational information if needed.

Adaptive algorithms will form the initial version of optimal instruction style. The algorithms function on the basis of predefined rules. The rules are created by experts in the field of pedagogy and in harmony with pedagogical and psychological principles. Below are examples of these rules:

- If the student's characteristics in the area of "Study Approach" $=75$ (a detail oriented student), then use the level of instruction 2 and then the level of instruction 1 in the order defined by other rules.

- If the student's characteristics in the area of "Motivation" $=-50$ (strongly unmotivated), then use the "Motivational Level" 3 (describes a practical benefit of this knowledge in details).

etc. [Kostolányová, 2011a]

Intuitive rules are the mainstay to create other rules. The intuitive rules will come from analysis and research concerning the evaluation of instruction and test results. Principles of a good instruction style are defined in the rules. Such an instruction style should motivate students with bad study approach to use more effective methods and study approach.

The "virtual teacher" is responsible for controlling the instruction as well as for measuring the students' progress. Measuring students' progress, detecting their level of knowledge and comprehension of the presented information is an essential part of the adaptive system. The whole instruction process is recorded: every "click" of the student, exact time spent in particular layers, changing of student's strategy, test results, etc. Recorded data serve as a source to make differential analysis.

- to verify the settings of student's characteristics;

- to verify the suitability of instruction support;

- to verify expert rules of the virtual teacher.

\section{Evaluation of Adaptive E-learning}

The Barborka system was tested in teaching of five different subjects. The purpose of this method is to gather early feedback for the prototype of adaptive learning system and its adaptive supports. More than one hundred students participated in study of one part of some subject. These students had to fill learning style questionnaire at the beginning of the study. Virtual teacher chose appropriate teaching style for each student on the basis of the filled learning style questionnaire. Filling the evaluation questionnaire at the end of the study was optional, and only 46 students filled it.

Reliability of this questionnaire was computed using Cronbach's alpha [Cronbach, 1951]. This statistic measures the innter consistency of the questionnaire by using formula (1). 
In this formula, $n$ is number of questions, $V_{i}$ is variance of scores on each question and $V_{\text {test }}$ is total variance of overall scores on the entire questionnaire. Value of the Cronbach's alpha for this questionnaire is 0.83 . Acceptable values should be greater then 0.7 , so we can consider that this questionnaire has good inner consitency and is reliable.

Evaluation questionnaire asked students the following:

- Evaluation of the learning style questionnaire

- Description of their learning style

- Material

- Usage of different depths and variants

- Level of comfort of the system

- Evaluation of adaptive e-learning

Linked data from learning style questionnaires and evaluation questionnaires were analyzed by association rules and correlations.

\section{Results}

New learning style was found on the basis of data analysis. Many students described their learning style as text underlining and making notes. Many students also complained about the system working slowly.

Correlation analysis was done between the sensory type measured in learning style questionnaire and students' favorite sensory type of variant (see Table 2). Expected correlation was found only with the kinesthetic type that correlated with interest in kinesthetic variant. Auditive type correlated with interest in verbal variant and with lack of interest in kinesthetic variant. Verbal type correlated with kinesthetic variant.

\begin{tabular}{|l|c|c|c|c|}
\hline & auditive & verbal & kinesthetic & visual \\
\hline Visual is best & -0.21 & 0.12 & -0.02 & 0.18 \\
\hline Kinesthetic is best & 0.18 & -0.33 & 0.23 & -0.09 \\
\hline Auditive is best & 0.12 & 0.10 & -0.19 & -0.10 \\
\hline $\begin{array}{l}\text { Kinesthetic is } \\
\text { interesting }\end{array}$ & -0.31 & -0.11 & 0.44 & 0.07 \\
\hline Auditive is interesting & 0.07 & -0.17 & 0.10 & 0.01 \\
\hline Visual is interesting & -0.11 & 0.23 & -0.26 & 0.16 \\
\hline Verbal is interesting & 0.38 & -0.17 & -0.13 & -0.18 \\
\hline
\end{tabular}

\section{Table 2: Correlation analysis}

Association analysis discovered no interesting rules. Only the connection between sensory types was confirmed.

Students evaluated their first experience with adaptive e-learning as normal (see Figure 3). $39 \%$ of students didn't know, $26 \%$ was negative and $35 \%$ positive. But the majority of students (see Figure 4) believe that the adaptive e-learning can be useful in the future. 


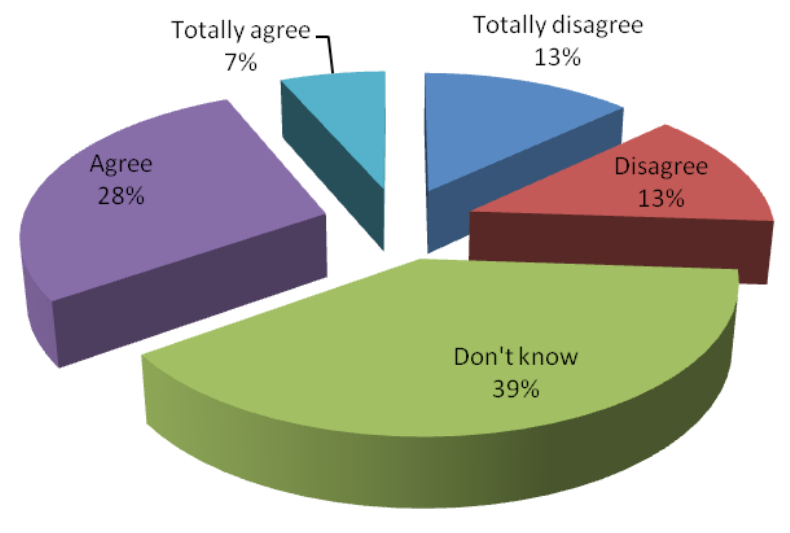

Figure 3: Is adaptive e-learning better than normal e-learning?

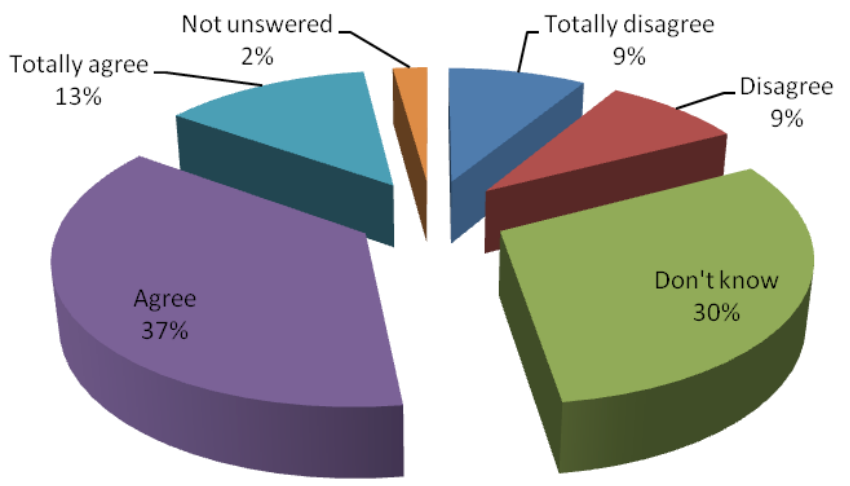

The clarity of the questionnaires and materials was evaluated positively (see Figure 5). Most of the students did not need any additional information or they found it in another depth.

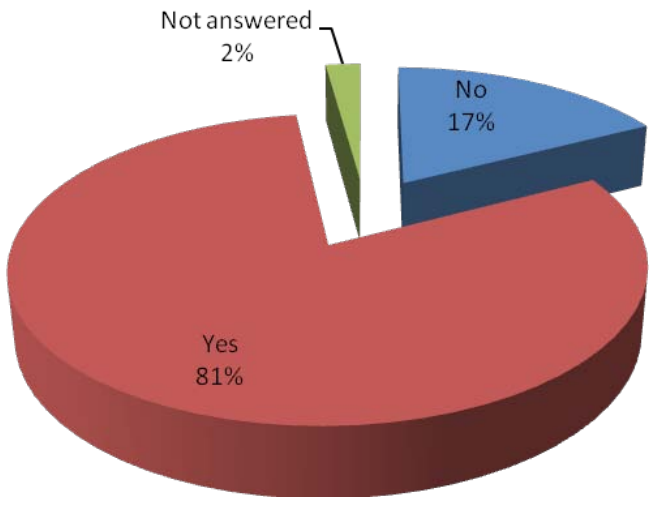

Figure 5: Were materials understandable?

Information in other depth was used only by half of the students and other sensory types of variants by $30 \%$. For most students the best variant was visual, and no one chose the verbal variant (see Figure 6).

Figure 4: Can adaptive e-learning be useful in the future? 


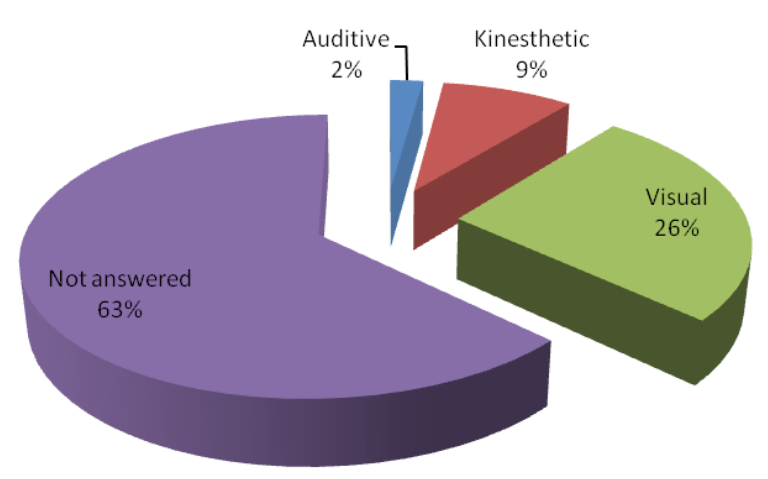

Figure 6: What sensory type of variant is best for you?

\section{Discussion}

Analysis was done only on a small sample of students, thus the conclusions are not entirely reliable. Correlation and association analyses did not confirm that sensory type measured by the learning style questionnaire determines what sensory type of variant is best for students. This correlation was discovered only with the kinesthetic type. This may be caused by incorrect measuring of the sensory type in the learning style questionnaire or by unsuitably created variants.

Students did not like the auditive variant according to the results of the evaluation questionnaire. This enabled authors of adaptive material to concentrate on more popular visual variants instead of auditive variants.

\section{Conclusion}

It should be noted that the execution of proposed adaptive instruction was not limited to theoretical work. Analysis of the software control system that automatically controls the whole instruction process is being done.

An adaptive LMS is implemented gradually on the basis of analysis results and is ready to be tested. When testing the adaptive LMS, some adjustments can be made in the area of student's characteristics as well as in the area of virtual teacher rules.

The advantage of this control system is that the theoretical parts implemented are of dynamic and parametrical nature. That means that if any adjustment needs to be made, it can be made by entering data in a database and not by adjusting the whole structure of the control system. Specifically the rules of the virtual teacher are saved in a special expert database. Among the standard user roles as "student", "author", "teacher" and "administrator" there is also the "expert" role. The "expert" is a specialist in the field of adaptive instruction who has access to the records and adjustments of parameters that control the adaptive instruction. Thus the "expert" can modify relevant data and instruction on the basis of teaching instruction analysis.

\section{References}

Brusilovsky, P., A. Kobsa a J.Vassileva, 1998. Adaptive Hypertext and Hypermedia. $1^{\text {st }}$ ed. Dordecht: Kluwer Academic Publishers. 268 p. ISBN 978-0-7923-4843-6.

Brusilovsky, P., 2001. Methods and Techniques of Adaptive Hypermedia. In User Modeling and User-Adapted Interaction, Special issue on adaptive hypertext and hypermedia. Kluwer academic publishers, vol. 6, no. 2-3, 87-129. 
Chih-Ming, C., Hahn-Ming L., Ya-Hui C., 2005. Personalized e-learning system using Item Response Theory, Computers\&Education, 44, s. 237-255. ISSN 0360-1315.

Cronbach, L. J., 1951. Coefficient alpha and the internal structure of tests. Psychometrika, 16(3), 297-334.

De Bra, P., et al., 2003. Aha! the Adaptive Hypermedia Architecture. Proceedings of the ACM Conference on Hypertext. 14, s. $81-84$.

Gagné, R. M., 1975. Podmínky učení. [Conditions of Learning] Praha: SPN. 287p.

Kalyuga, S., Sweller, J., 2005. Rapid dynamic assessment of expertise to improve the efficiency of adaptive e-learning, Educational Technology Research and Development, 53, s. 83-93

Komenský, J. A., 1947. Analytická didaktika. [Analytical Didactics] Praha: SPN.

Komenský, J. A., 1948. Didaktika velká. [Great Didactics] Brno: Komenium.

Kostolányová, K., J. Šarmanová a O. Takács, 2010. Adaptable Educational Supports. In Information and Communication Technology in Education. Ostrava: University of Ostrava. p. 117121. ISBN 978-80-7368-775-5

Kostolányová, K., J. Šarmanová a O. Takács, 2011a. Adaptation of teaching process based on a students individual learning needs. In Journal on Efficiency and Responsibility in Education and Science. y. 2011, vol. 1, p. 3-17.

Kostolányová, K., J. Šarmanová a O. Takács, 2011b Classification of Learning Styles for Adaptive Education. In The New Educational Review. y. 2011, vol. 23, p. 199-212.

Kostolányová, K., 2011c Design of study materials structure for adaptive instruction. In Information and Communication
Technology in Education. Ostrava: University of Ostrava. p. 193201. ISBN 978-80-7368-979-7

Kostolányová, K. E-learning form of adaptive instruction: Conference Proceedings. DIVAI 2012 - 9th International Scientific Conference on Distance Learning in. Nitra: Faculty of Natural Sciences, Constantine the Philosopher University in Nitra, 2012. s. 194-201. [2012]. ISBN 978-80-558-0092-9

Kulič, V., 1980. Některá kritéria efektivity učení a vyučování a metody jejího zjištování. [Some Criteria of Efficiency of Learning and Teaching and Methods for its Discovery] Pedagogika, 30, p. 677-698.

Paramythis A., Loidl-Reisinger S., 2003, Adaptive Learning Environments and e-Learning Standards, ECEL, Linz, Austria, pp. 181-194.

Ruiz, M.P.P; Barriales, S.O., 2003. Feijoo.net: An Approach to Personalized E-learning Using Learning Styles, ICWE'03 Proceedings of the 2003 international conference on Web engineering, Springer Berlin, s. 151-154. ISBN 978-3-540-40522-1. 